Check for updates

Cite this: Mater. Adv., 2021, 2, 5062

Received 19th April 2021 Accepted 16th June 2021

DOI: $10.1039 / d 1 m a 00363 a$

rsc.li/materials-advances

\section{A substrate surface alloy strategy for integrated sulfide electrodes for sodium ion batteries with superior lifespan $\dagger$}

\author{
Li-Feng Zhou, ${ }^{a}$ Tao Du, (D) *a Li-Ying Liu, ${ }^{a}$ Yi-Song Wang ${ }^{a}$ and Wen-Bin Luo (D) *ab
}

\begin{abstract}
A binder-free free-standing sulfide electrode was synthesized and fabricated with a three dimensional (3D) porous nanostructure. In order to strengthen the adhesion between the substrate and active materials, the surface of the employed nickel foam substrate was modified by an alloy strategy of pre-planting copper seeds onto the nickel foam surface. The obtained electrode presents excellent electrochemical performance in sodium-ion batteries. It delivers a high reversible specific capacity of $1107 \mathrm{~mA} \mathrm{~h} \mathrm{~g}$ g $^{-1}$ at $0.1 \mathrm{~A} \mathrm{~g}^{-1}$ with an initial coulombic efficiency of $\mathbf{8 5 . 6 \%}$. Excellent rate and cycle performances were also exhibited. Even at $2 \mathrm{~A} \mathrm{~g}^{-1}$, it still can deliver a capacity of $475 \mathrm{~mA} \mathrm{~h} \mathrm{~g}^{-1}$. The capacity retention is $61.8 \%$ after 1000 cycles at $0.5 \mathrm{~A} \mathrm{~g}^{-1}$.
\end{abstract}

\section{Introduction}

Sodium-ion batteries (SIBs) are being rapidly developed because they are considered as one of the most promising candidates to replace lithium ion batteries (LIBs) based on their inherent merits of abundant and economically efficient renewable resources. ${ }^{1-5}$ Over the course of long-term global research, there are many achievements based on the potential material exploration and modification. Industrial SIB prototypes have been created and researchers have started to experiment with potential applications. Several issues have appeared during the trial period. ${ }^{6-12}$ Among these is the significant issue of unsatisfactory cycling lifespan. To address this issue, two dimensional transition metal dichalcogenides (TMDs), such as $\mathrm{MoS}_{2},{ }^{13,14}$ $\mathrm{TiS}_{2},{ }^{15,16} \mathrm{TaS}_{2},{ }^{17} \mathrm{WS}_{2},{ }^{18,19} \mathrm{MoSe}_{2},{ }^{20,21}$ and $\mathrm{WSe}_{2},{ }^{22,23}$ are attracting increasing attention and widely employed as active materials owing to their overwhelming advantages such as large interlayer

\footnotetext{
${ }^{a}$ State Environmental Protection Key Laboratory of Eco-Industry,

Northeastern University, Shenyang 110004, China.

E-mail: luowenbin@smm.neu.edu.cn

${ }^{b}$ Institute for Energy Electrochemistry and Urban Mines Metallurgy,

School of Metallurgy, Northeastern University, Shenyang, China

$\dagger$ Electronic supplementary information (ESI) available. See DOI: 10.1039/ d1ma00363a
}

spacing and high reversible conversion efficiency. The inherent semiconductor property, however, slows the reaction kinetics resulting from the unsatisfactory electronic conductivity. This sluggish reaction kinetic rate will influence the electrochemical performance, particularly the rate performance. ${ }^{24-26}$ Therefore, much effort have been made to realize high rate capability and satisfactory lifespan by accelerating the electronic conductivity, such as employing high electronic conductive substrates and designing appropriate morphology. For example, three-dimensional porous-structured substrates, such as graphene or metal foam, are widely utilised owing to their high conductivity and porous structure. ${ }^{27-29}$ Among them, nickel foams (Ni) have always received increasing attention because of their high economic efficiency and mature practical product. Therefore, various active materials are deposited on the surface of $\mathrm{Ni}$ foams to realize an integrated electrode for battery application, particularly binderfree free-standing structure. However, owing to the weak adhesion between the substrate and deposited active materials, the active materials are easily peeled off from $\mathrm{Ni}$ foam during the long-term cycling period, thus dramatically decreasing the cycling lifespan..$^{30-32}$

Herein, the surface of a Ni foam was modified by an alloy strategy of pre-planting copper seeds on the nickel foam surface to strengthen the adhesion between the substrate and active materials. First, a NiCu alloy thin layer was formed on the surface of Ni foam and Ni-Cu sulfide (NCS) nanosheets were in situ growing to form a porous flower-like architecture. It was used as a binder-free and free-standing electrode for a sodium ion battery. This architecture has also made great contribution to the enhanced electrochemical performance by the inherent advantages of shorter paths for ion insertion and extraction, larger contact area for more sodium diffusion pathways and superior electrolyte penetration. The as-prepared 3D-structured electrodes exhibit a high specific capacity of $1107 \mathrm{~mA} \mathrm{~h} \mathrm{~g}^{-1}$ with an initial coulombic efficiency of $85.6 \%$. It also presents superior rate performance, even at the current density of $2 \mathrm{~A} \mathrm{~g}^{-1}$, delivering a capacity of $475 \mathrm{~mA} \mathrm{~h} \mathrm{~g}^{-1}$. It also exhibited excellent cycle lifespan with $61.8 \%$ capacity retention after 1000 cycles at $0.5 \mathrm{~A} \mathrm{~g}^{-1}$. 


\section{Results and discussion}

The experimental schematic is described, as shown in Fig. 1a. First, the surface of Ni foam was modified by the alloy technology and a thin layer of the NiCu alloy was obtained. Second, $\mathrm{Ni}-\mathrm{Cu}$ hydroxide precursors were in situ grown on the surface of the $\mathrm{NiCu}$ alloy by a hydrothermal method. Finally, Ni-Cu hydroxide was converted into the corresponding $\mathrm{Ni}-\mathrm{Cu}$ sulfide (NCS) by further hydrothermal sulfuration reaction. The morphologies of $\mathrm{Ni}-\mathrm{Cu}$ hydroxide were characterized by field emission scanning electron microscopy (FESEM), as shown in Fig. 1b. The SEM image shows that the Ni-Cu hydroxide on the surface of the $\mathrm{Ni}$ foam consists of numerous one-dimensional twisted nanowires, with a diameter of about $10 \mathrm{~nm}$. After the sulfuration reaction, the obtained NCS shows a highly uniform flower-like structure with a size of about $1 \mu \mathrm{m}$, as shown in Fig. 1(c-e), composed of numerous nanosheets (Fig. 1d). The transmission electron microscopy (TEM) image (the inset of Fig. 1d) further confirms a slim floc-like morphology on the surface of nanosheets. In areas of the nanosheets in Fig. 1e, clear lattice stripes with different interplanar distances of $2.87 \AA$ and $2.40 \AA$ are observed, which correspond to the (110) and (102) planes of the hexagonal phase structure. In Fig. S1 (ESI $\dagger$ ), the strong and sharp peaks at $44.6^{\circ}, 52.0^{\circ}$ and $76.6^{\circ}$ (JCPDS, 70-1849) can be assigned to the $\mathrm{Ni}$ foam substrate. Several representative peaks can be attributed to the $\mathrm{Ni}-\mathrm{Cu}$ sulfide materials.

The chemical state and elemental composition of NCS is further characterized by X-ray photoelectron spectroscopy (XPS). The existence of $\mathrm{Cu}, \mathrm{Ni}, \mathrm{O}, \mathrm{C}$ and $\mathrm{S}$ is proved in the survey spectrum $^{33-36}$ (Fig. 2a). With C 1s $(284.6 \mathrm{eV})$ as the reference,

(a)
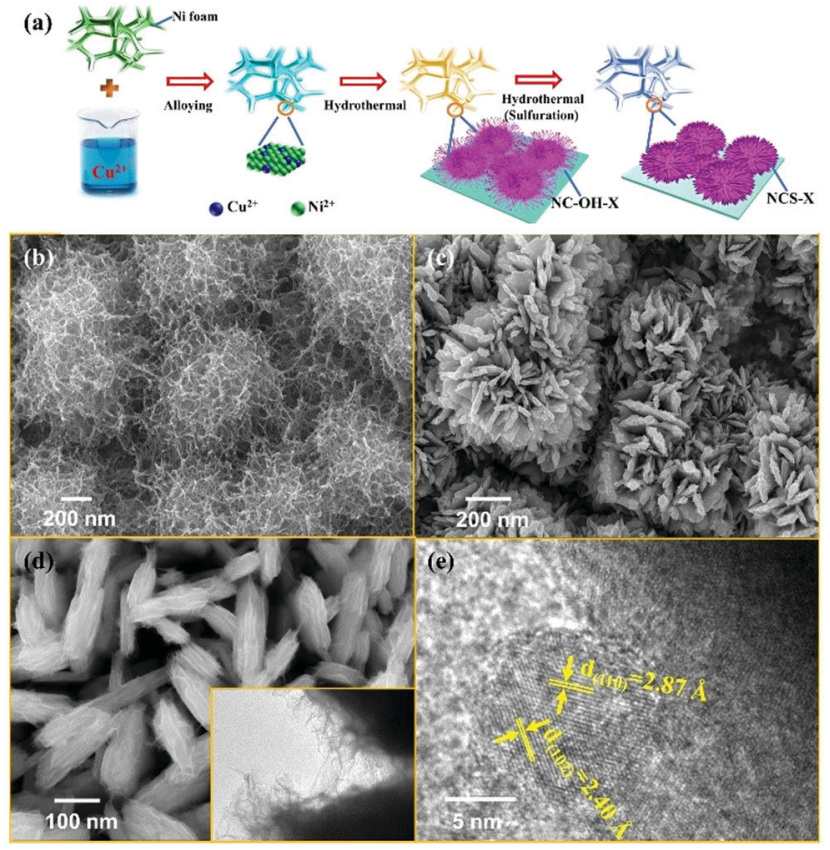

Fig. 1 (a) The experimental schematic of NCS; the low SEM images of (b) Ni-Cu hydroxide and (c) NCS; (d) SEM image of nanosheets (the inset is the TEM image); (e) the high resolution TEM image of nanosheets.
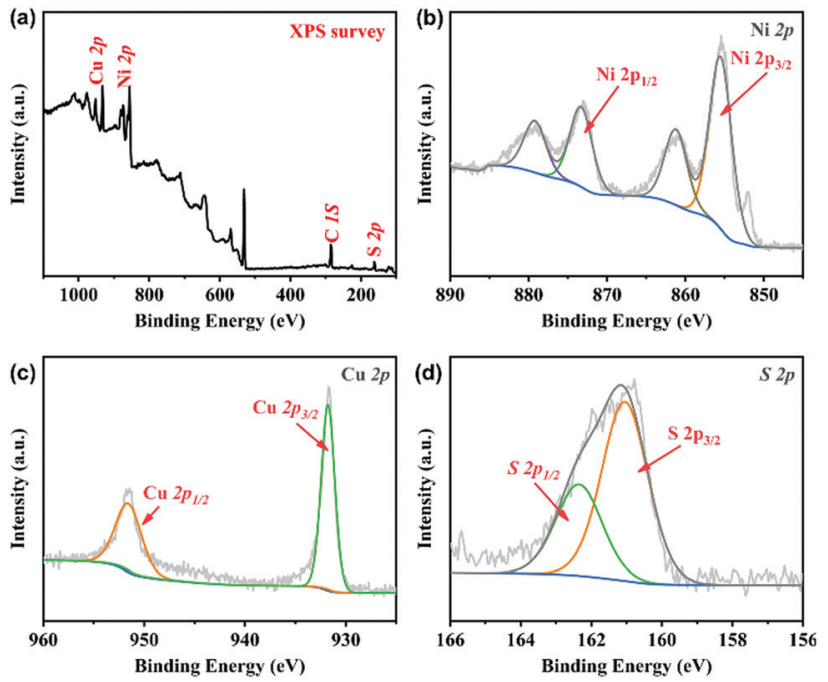

Fig. 2 XPS spectroscopy of (a) survey spectrum and high-resolution scans of (b) Ni 2p, (c) Cu 2p, and (d) S $2 p$.

Ni 2p, Cu 2p and S 2p XPS peak-fitting results of NCS are shown in Fig. $2(\mathrm{~b}-\mathrm{d})$, respectively. In the $\mathrm{Ni} 2 \mathrm{p}$ spectrum, two main peaks at 873.6 and $855.8 \mathrm{eV}$ could be assigned to $\mathrm{Ni} 2 \mathrm{p}_{1 / 2}$ and $\mathrm{Ni}$ $2 \mathrm{p}_{3 / 2}$, respectively, and the other two peaks correspond to the accompanied satellite peaks of $\mathrm{Ni} 2 \mathrm{p}_{1 / 2}$ and $\mathrm{Ni} 2 \mathrm{p}_{3 / 2}$. In the $\mathrm{Cu}$ high-resolution XPS, the peaks at 951.6 and $931.8 \mathrm{eV}$ correspond to $2 \mathrm{p}_{3 / 2}$ and $2 \mathrm{p}_{1 / 2}$ of $\mathrm{Cu}$. For $\mathrm{S} 2 \mathrm{p}$, the peaks at $162.1 \mathrm{eV}$ and $160.9 \mathrm{eV}$ originate from $\mathrm{S} 2 \mathrm{p}_{1 / 2}$ and $\mathrm{S} 2 \mathrm{p}_{3 / 2}$, respectively. Nitrogen adsorption-desorption isotherm measurements were conducted to examine the porous nature of the NCS composite. The profile of the $\mathrm{N}_{2}$ isotherms in Fig. S2 (ESI $\dagger$ ) is identified as type-IV with a small hysteresis loop, confirming the existence of a mesoporous structure. The isotherms are characteristic of micropore filling in the low-pressure region and display a mild adsorption in the high-pressure region, indicating that both micropore and mesopore filling occurred and the amount is very small. The Brunauer-Emmett-Teller specific surface area of the composite is $94.5 \mathrm{~m}^{2} \mathrm{~g}^{-1}$, and the total pore volume is $0.179 \mathrm{~mL} \mathrm{~g}^{-1}$ (Fig. S3, ESI $\dagger$ ). The average pore size of the multilevel pore structure is $7.4 \mathrm{~nm}$. The mesopores have a favourable effect on the transport of electrolyte ions.

To evaluate the electrochemical performance of NCS, twoelectrode configuration was applied using sodium metal as the reference and counter electrode and binder-free NCS as the anode material (Fig. 3 and Fig. S4, ESI $\dagger$ ). The charge/discharge profiles and CV curves could effectively elucidate the oxidation/ reduction of the sodium storage process. The initial three charge and discharge curves of NCS are shown in Fig. 3a. The voltage plateaus near $0.9 \mathrm{~V}$ in the first discharge process could be attributed to the conversion reaction in which sulfide converted into $\mathrm{Ni}, \mathrm{Cu}$ particles, accompanied by the formation of a solid electrolyte layer (SEI). In addition, the high rate capability of such electrodes is presented in Fig. 3b. It delivers reversible specific capacities of $1050,949,802,662,461 \mathrm{~mA} \mathrm{~h} \mathrm{~g}^{-1}$ at $0.1,0.2,0.5,1.0$ and $2.0 \mathrm{Ag}^{-1}$, respectively. When the current density 

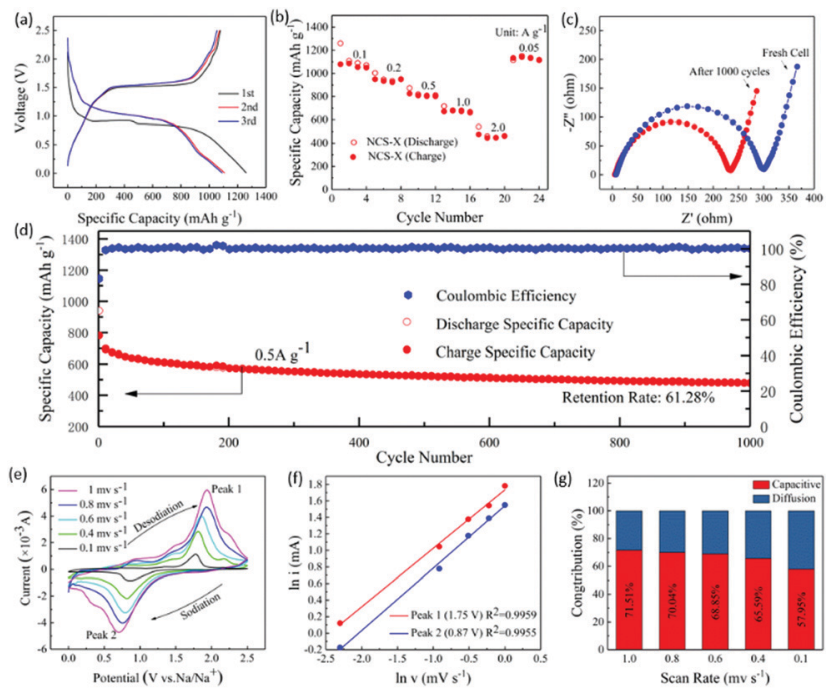

Fig. 3 Electrochemical measurements of the NCS electrode in sodium ion battery. (a) The initial three charge and discharge curves at $0.5 \mathrm{~A} \mathrm{~g}^{-1}$; (b) rate performance; (c) electrochemical impedance spectroscopy of NCS; (d) cyclic properties at $0.5 \mathrm{~A} \mathrm{~g}^{-1}$; (e) CV curves at different scan rates of NCS; (f) $\log / v s . \log v$ at different oxidation and reduction states; (g) normalized contribution ratio of capacitive capacities at different scan rates.

was back to $0.05 \mathrm{Ag}^{-1}$, a highly stable capacity of $1117 \mathrm{~mA} \mathrm{~h} \mathrm{~g}^{-1}$ was resumed for the NCS electrode, indicating good cycling stability and rapid reaction kinetics, which is ascribed to the well-dispersed and highly conductive NCS electrode. The improved electrochemical properties are related to the internal resistance of the electrode, including bulk impedance and interfacial impedance. Before and after cycling, the Nyquist plots were collected (Fig. 3c). The compressed semicircle in the high/middle-frequency region represents charge-transfer resistance $\left(R_{\mathrm{ct}}\right)$ at the interface of the composite. Further, the oblique straight line in the low-frequency region corresponds to ion diffusion, which stands for the Warburg impendence $\left(Z_{\mathrm{w}}\right) \cdot{ }^{37}$ After cycles, the $R_{\mathrm{ct}}$ decreases apparently, indicating improved interfacial wettability and sodium ion diffusion with cycling. It further reveals that the cell with the NCS interlayer possesses good electrochemical kinetics, which reflects the good cycle performance of the cell. In addition, the slope in the low frequency range is same. These interconnected nanosheets with high conductivity are beneficial for fast electron transport during the electrochemical process. Fig. 3d shows the cycle performance and corresponding coulombic efficiency of NCS at $0.5 \mathrm{~A} \mathrm{~g}^{-1}$. It could deliver a discharge capacity of $940 \mathrm{~mA} \mathrm{~h} \mathrm{~g}^{-1}$, and a charge capacity of $478 \mathrm{~mA} \mathrm{~h} \mathrm{~g}^{-1}$ can still be achieved after 1000 long cycles and the retention can reach $61.3 \%$. Compared with the previously reported transition-metal dichacolgenide electrodes (Table S1, ESI $\dagger$ ), the electrochemical performance of this material is comparable. ${ }^{32-37}$ The mesoporous nanostructure and large surface area could provide efficient ion and electron transport, resulting in faster kinetics for faradaic energy storage.

To further reveal the electrochemical kinetics of the NCS electrode, cyclic voltammetry (CV) measurements under different scan rates (0.1-1.0 $\mathrm{mV} \mathrm{s}^{-1}$ ) were conducted (Fig. 3e). At
$0.1 \mathrm{mV} \mathrm{s}^{-1}$, the CV curve possesses a pair of redox peaks, plots of the cathodic process at $\sim 0.87 \mathrm{~V}$ and the anodic process at $\sim 1.75 \mathrm{~V}$, which are in accordance with the plateaus of the discharge and charge curves (Fig. 3a). As the scan rate increased, the $\mathrm{CV}$ curves display similar shapes with the cathodic and anodic peak potentials gradually shifting towards the positive/negative potential and the redox current increases, indicating diffusion-controlled reaction kinetics. A related analysis can be performed regarding the behaviour of the peak current by assuming that the current ( $i$ ) obeys a power law relationship with the scan rate $(v):^{38}$

$$
i=a v^{b}
$$

In this equation, $a$ is a constant, and the $b$ value can change between 0.5 and 1.0. The $b$ value is given by the slope of the $\ln I$ $v s$. $\ln v$ plots. If $b$ approaches 1 , the system is mainly controlled by capacitance. If $b$ is close to 0.5 , it represents a diffusion limited process. For simplifying the computation procedure, (1) can be rewritten as:

$$
\ln i=b \times \ln v+\ln a
$$

The relationship of $\ln v-\ln i$ is shown in Fig. 3f. Also, the $\mathrm{b}$ values at different oxidation and reduction states are 0.75 and 0.71 with $R_{2}$ up to 0.9955 and 0.9959 , respectively. It indicates that the electrochemical reaction of NCS is controlled by the combination of capacitive and diffusion processes. Moreover, the relationship $i=a v^{b}$ can be separated into two parts including capacitive $\left(k_{1} v\right)$ and diffusion limited effects $\left(k_{2} v^{1 / 2}\right)$, as follows: ${ }^{39-41}$

$$
i(v)=k_{1} v+k_{2} v^{\frac{1}{2}}
$$

Here, $v$ is the scan rate, and $i$ is the total current response at a fixed potential $(V)$, which can be separated into two mechanisms. For simplifying the computation procedure, (3) can be rewritten as:

$$
\frac{i(v)}{v^{\frac{1}{2}}}=k_{1} v^{\frac{1}{2}}+k_{2}
$$

Calculated and fitted data are illustrated in Fig. S5 (ESI $\dagger$ ). For example, approximately $71.5 \%$ of the total current comes from capacitive contribution at a scan rate of $1 \mathrm{mV} \mathrm{s}^{-1}$ for NCS. Capacitive-controlled currents predominately concentrated in the peak regions. The remaining regions are almost entirely diffusion controlled, which is in accordance with the result of $b$-value. Fig. $3 \mathrm{~g}$ summarizes the contribution of the capacitive behavior under various scan rates. The capacitive contributions are $57.9 \%, 65.6 \%, 68.9 \%, 70.0 \%$, and $71.5 \%$ under the scan rates of $0.1,0.4,0.6,0.8$, and $1.0 \mathrm{mV} \mathrm{s}^{-1}$, respectively. The kinetic analysis clearly exhibits that the capacitive chargestorage does occupy a high proportion of the total capacity and increases with the increase in the scan rate.

Ex situ XRD tests were carried out to investigate the storage mechanism of NCS electrodes. Fig. 4 shows the XRD patterns of NCS electrodes at different charge-discharge states. At $0.9 \mathrm{~V}$, the peak of $\mathrm{Na}_{2} \mathrm{~S}$ appeared, while the peaks of $\mathrm{Ni}_{3} \mathrm{~S}_{2}$ and $\mathrm{Cu}_{2} \mathrm{~S}$ 


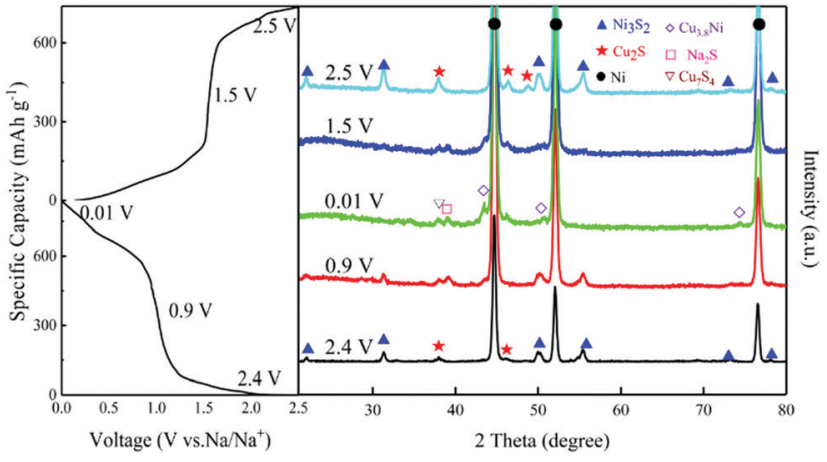

Fig. 4 Ex situ XRD of NCS during charge and discharge.

gradually disappeared. At $0.01 \mathrm{~V}$, the diffraction peaks of $\mathrm{Na}_{2} \mathrm{~S}$ and $\mathrm{Cu}_{3.8} \mathrm{Ni}$ alloy are obviously present after discharge. Possible total electrochemical reactions during discharge process are shown below:

$\mathrm{Ni}_{3} \mathrm{~S}_{2}+5.7 \mathrm{Cu}_{2} \mathrm{~S}+15.4 \mathrm{Na}^{+}+15.4 \mathrm{e}^{-} \rightarrow 7.7 \mathrm{Na}_{2} \mathrm{~S}+11.4 \mathrm{Cu}+3 \mathrm{Ni}$

This conjecture matches with the $\mathrm{CV}$ curves and typical discharge and charge profiles above. The pattern at $1.5 \mathrm{~V}$ still shows the representative peaks of $\mathrm{Na}_{2} \mathrm{~S}$ and the alloy, but the intensity reduced during the charge process. ${ }^{42}$ The pattern at $2.5 \mathrm{~V}$ is almost the same as that of the fresh NCS encouragingly, indicating that a reversible conversion reaction occurs during the first cycle. The possible total desodiation reactions in the charge process are shown below:

$$
\begin{aligned}
& (x+2) \mathrm{Na}_{2} \mathrm{~S}+2 x \mathrm{Cu}+3 \mathrm{Ni} \rightarrow \mathrm{Ni}_{3} \mathrm{~S}_{2}+x \mathrm{Cu}_{2} \mathrm{~S} \\
& \quad+2(x+2) \mathrm{Na}^{+}+2(x+2) \mathrm{e}^{-} \quad(x<5.7)
\end{aligned}
$$

\section{Conclusions}

A binder-free free-standing structured sulphide electrode was synthesized and fabricated by the hydrothermal method. In order to strengthen the adhesion between the substrate and active materials, the surface of the nickel foam was modified by alloy strategies. The obtained three-dimensional porousintegrated electrode composited by numerous sulfide nanosheets provides much more active sites and the special architecture can also short the diffusion path of the electrolyte and electron during charge and discharge, resulting in faster kinetics for energy storage. It delivers an initial coulombic efficiency of $85.6 \%$ with a high reversible specific capacity of $1107 \mathrm{~mA} \mathrm{~h} \mathrm{~g}{ }^{-1}$ at $0.1 \mathrm{~A} \mathrm{~g}^{-1}$. The electrode exhibited excellent cycling performance, with $61.3 \%$ retention after 1000 long cycles at $0.5 \mathrm{~A} \mathrm{~g}^{-1}$.

\section{Conflicts of interest}

There are no conflicts to declare.

\section{Acknowledgements}

This work was supported by LiaoNing Revitalization Talents Program (XLYC2007155), the Fundamental Research Funds for the Central Universities (N2025018, N2025009), the National Key Research and Development Project (No. 2019YFC1905200 and 2017YFB0304001), the National Natural Science Foundation of China (No. 51904073), and Fundamental Research Funds for the central Universities (Grants N182508027).

\section{References}

1 A. S. Arico, P. Bruce, B. Scrosati, J. M. Tarascon and W. Van Schalkwijk, Nat. Mater., 2005, 4, 366-377.

2 C. Liu, F. Li, L.-P. Ma and H.-M. Cheng, Adv. Mater., 2010, 22, E28.

3 J. M. Tarascon and M. Armand, Nature, 2001, 414, 359-367.

4 N. Yabuuchi, K. Kubota, M. Dahbi and S. Komaba, Chem. Rev., 2014, 114, 11636-11682.

5 Z. Yan, Q.-W. Yang, Q. Wang and J. Ma, Chin. Chem. Lett., 2020, 31, 583-588.

6 M. Yang, Q. Ning, C. Fan and X. Wu, Chin. Chem. Lett., 2021, 32, 895-899.

7 H. Huang, X. Luo, Y. Yao, X. Zhou, Y. Jiang, C. Guo, J. Liu, $\mathrm{X}$. Wu and Y. Yu, InfoMat, 2021, 3, 421-431.

8 B. Wang, Y. Cheng, H. Su, M. Cheng, Y. Li, H. Geng and Z. Dai, ChemSusChem, 2020, 13, 4078-4085.

9 Y.-Y. Wang, B.-H. Hou, J.-Z. Guo, Q.-L. Ning, W.-L. Pang, J. Wang, C.-L. Lu and X.-L. Wu, Adv. Energy Mater., 2018, 8, 9218-9225.

10 D.-H. Liu, W.-H. Li, Y.-P. Zheng, Z. Cui, X. Yan, D.-S. Liu, J. Wang, Y. Zhang, H.-Y. Lu, F.-Y. Bai, J.-Z. Guo and X.-L. Wu, Adv. Mater., 2018, 30, 1706317.

11 L. Xue, S. V. Savilov, V. V. Lunin and H. Xia, Adv. Funct. Mater., 2018, 28, 1705836.

12 L. Xue, Q. Zhang, X. Zhu, L. Gu, J. Yue, Q. Xia, T. Xing, T. Chen, Y. Yao and H. Xia, Nano Energy, 2019, 56, 463-472.

13 M. Acerce, D. Voiry and M. Chhowalla, Nat. Nanotechnol., 2015, 10, 313-318.

14 K. Chang and W. Chen, ACS Nano, 2011, 5, 4720-4728.

15 T. Liu, X. Zhang, M. Xia, H. Yu, N. Peng, C. Jiang, M. Shui, Y. Xie, T.-F. Yi and J. Shu, Nano Energy, 2020, 67, 104295.

16 J. Tang, X. Huang, T. Lin, T. Qiu, H. Huang, X. Zhu, Q. Gu, B. Luo and L. Wang, Energy Storage Mater., 2020, 26, 550-559.

17 Q. Peng, Z. Wang, B. Sa, B. Wu and Z. Sun, ACS Appl. Mater. Interfaces, 2016, 8, 13449-13457.

18 J. Duan, S. Chen, B. A. Chambers, G. G. Andersson and S. Z. Qiao, Adv. Mater., 2015, 27, 4234-4241.

19 T. Lei, W. Chen, J. Huang, C. Yan, H. Sun, C. Wang, W. Zhang, Y. Li and J. Xiong, Adv. Energy Mater., 2017, 7, 1601843.

20 F. Niu, J. Yang, N. Wang, D. Zhang, W. Fan, J. Yang and Y. Qian, Adv. Funct. Mater., 2017, 27, 1700522. 
21 Y. Shi, C. Hua, B. Li, X. Fang, C. Yao, Y. Zhang, Y.-S. Hu, Z. Wang, L. Chen, D. Zhao and G. D. Stucky, Adv. Funct. Mater., 2013, 23, 1832-1838.

22 Y. Y. Lee, G. O. Park, Y. S. Choi, J. K. Shon, J. Yoon, K. H. Kim, W.-S. Yoon, H. Kim and J. M. Kim, RSC Adv., 2016, 6, 14253-14260.

23 B. Liu, T. Luo, G. Mu, X. Wang, D. Chen and G. Shen, ACS Nano, 2013, 7, 8051-8058.

24 G. Fang, J. Zhou, A. Pan and S. Liang, ACS Energy Lett., 2018, 3, 2480-2501.

25 P. K. Nayak, L. Yang, W. Brehm and P. Adelhelm, Angew. Chem., Int. Ed., 2018, 57, 102-120.

26 J. Pang, R. G. Mendes, A. Bachmatiuk, L. Zhao, H. Q. Ta, T. Gemming, H. Liu, Z. Liu and M. H. Rummeli, Chem. Soc. Rev., 2019, 48, 72-133.

27 D. Aurbach, B. Markovsky, I. Weissman, E. Levi and Y. Ein-Eli, Electrochim. Acta, 1999, 45, 67-86.

28 W. Chen, S. Li, C. Chen and L. Yan, Adv. Mater., 2011, 23, 5679 .

29 H. Hou, C. E. Banks, M. Jing, Y. Zhang and X. Ji, Adv. Mater., 2015, 27, 7861-7866.

30 Y. Jin, H. Wang, J. Li, X. Yue, Y. Han, P. K. Shen and Y. Cui, Adv. Mater., 2016, 28, 3785-3790.

31 Z. Tang, C.-h. Tang and H. Gong, Adv. Funct. Mater., 2012, 22, 1272-1278.
32 C. Yuan, L. Yang, L. Hou, L. Shen, X. Zhang and X. W. Lou, Energy Environ. Sci., 2012, 5, 7883-7887.

33 Y. Lu, B. Li, S. Zheng, Y. Xu, H. Xue and H. Pang, Adv. Funct. Mater., 2017, 27, 1703949.

34 S. S. Park, Y. Tulchinsky and M. Dinca, J. Am. Chem. Soc., 2017, 139, 13260-13263.

35 Z. Zheng, H.-H. Wu, H. Chen, Y. Cheng, Q. Zhang, Q. Xie, L. Wang, K. Zhang, M.-S. Wang, D.-L. Peng and X. C. Zeng, Nanoscale, 2018, 10, 22203-22214.

36 W. Zhou, X. Cao, Z. Zeng, W. Shi, Y. Zhu, Q. Yan, H. Liu, J. Wang and H. Zhang, Energy Environ. Sci., 2013, 6, 2216-2221.

37 K. Zeng, X. Li, Z. Wang, H. Guo, J. Wang, T. Li, W. Pan and K. Shih, Electrochim. Acta, 2017, 247, 795-802.

38 W. Ren, H. Zhang, C. Guan and C. Cheng, Adv. Funct. Mater., 2017, 27, 1702116.

39 R. Sun, S. Liu, Q. Wei, J. Sheng, S. Zhu, Q. An and L. Mai, Small, 2017, 13, 28834239.

40 K. Zhang, M. Park, L. Zhou, G. H. Lee, J. Shin, Z. Hu, S. L. Chou, J. Chen and Y. M. Kang, Angew. Chem., Int. Ed., 2016, 55, 12822-12826.

41 D. Xu, C. Chen, J. Xie, B. Zhang, L. Miao, J. Cai, Y. Huang and L. Zhang, Adv. Energy Mater., 2016, 6, 1501929.

42 J. Li, D. Yan, T. Lu, W. Qin, Y. Yao and L. Pan, ACS Appl. Mater. Interfaces, 2017, 9, 2309-2316. 